\title{
Recommendation of RILEM TC 258-AAA: RILEM AAR-0 outline guide to the use of RILEM methods in the assessment of the alkali-reactivity potential of concrete
}

\author{
Terje F. Rønning • Børge Johannes Wigum • Jan Lindgård • Philip Nixon • \\ Ian Sims
}

Accepted: 23 March 2021 / Published online: 26 October 2021

(C) The Author(s) 2021, corrected publication 2022

\begin{abstract}
This outline guide, RILEM AAR-0, describes how to use the following test methods in the assessment of the alkali reactivity potential of
\end{abstract}

Chair: Børge Johannes WIGUM

Deputy Chair: Jan LINDGÅRD

TC Members: Mark G. ALEXANDER, Mario BERRA, Ingmar BORCHERS, Maarten BROEKMANS, Rene BRUECKNER, João CUSTÓDIO, Vinh DAO, Mario DE ROOIJ, Klaartje DE WEERDT, Josée DUCHESNE, Rui Miguel FERREIRA, Benoît FOURNIER, Sue FREITAG, Ricardo GARCIAROVES LOZA, Eric GIANNINI, Colin GIEBSON, Michal A. GLINICKI, R. Doug HOOTON, Jason H. IDEKER, Patricija KARA DE MAEIJER, Yuichiro KAWABATA, Stefan KRISPEL, Selmo C. KUPERMAN, Andreas LEEMANN, Lech LEWCZUK, Jan LINDGÅRD, Tung Chai LING, QingFeng LIU, Renaud-Pierre MARTIN, Esperanza MENENDEZ MENDEZ, Birgit MENG, Urs MÜLLER, Christoph MÜLLER, Bård M. PEDERSEN, Gilles PLUSQUELLEC, Terje F. RØNNING, Leandro SANCHEZ, Antonio SANTOS SILVA, Ignacio SEGURA, Katrin SEYFARTH, Gintautas SKRIPKIUNAS, Zhenguo SHI, Ian SIMS, Suvimol SUJJAVANICH, Michael D. A. THOMAS, Børge Johannes WIGUM, (late) Jonathan WOOD, Kazuo YAMADA

T. F. Rønning · B. J. Wigum ( $₫)$

HeidelbergCement Northern Europe, Lilleakerveien 2B, 0283 Oslo, Norway

e-mail: BorgeJohannes.Wigum@heidelbergcement.com

T. F. Rønning

e-mail: terje.ronning@heidelbergcement.com

J. Lindgård

SINTEF Community, Torgarden, P.O. Box 4760,

7465 Trondheim, Norway

e-mail: jan.lindgard@sintef.no aggregates and concrete. The test methods included are:

AAR-1.1 Petrographic examination method (2016)

AAR-1.2 Recommended guidance (Atlas) (2016)

AAR-2 Accelerated mortar-bar method (2016)

AAR-3.1 \& AAR-3.2 Concrete prism test $-38^{\circ} \mathrm{C}$ (2016)

AAR-4.1 Concrete prism test $-60{ }^{\circ} \mathrm{C}$ (2016)

AAR-5 Screening test for carbonate aggregates (2016)

AAR-8 Determination of alkalis releasable by aggregates in concrete (2021)

AAR-10.1 \& 10.2 Concrete prism test $-38{ }^{\circ} \mathrm{C}$ (2021)

AAR-11.1, $11.2 \& 11.3$ Concrete prisms test$60{ }^{\circ} \mathrm{C}$ test method (2021)

AAR-12.1, $12.2 \& 12.3$ Concrete prisms $-60{ }^{\circ} \mathrm{C}$ test method with alkali supply (2021)

AAR-13 Application of alkali-wrapping for concrete prism testing (2021)

P. Nixon

England, UK

e-mail: tyrrellnixon@btinternet.com

I. Sims

RSK Environment Ltd, Hemel Hempstead, UK

e-mail: isims@rsk.co.uk 
This recommendation has been prepared by a working group within RILEM TC 258-AAA. The recommendation has been reviewed and approved by all members of the TC.

\section{Part one: concept and overview}

\subsection{Introduction and scope}

AAR-0 (2021) is extended from its previous edition [9] and now provides guidance on the integrated use of the assessment procedures described in

- Part 1: Petrographic examination method [9] and AAR-1.2 Recommended guidance (Atlas) for use with AAR-1 (2016) [19].

- AAR-2 Detection of potential alkali-reactivityAccelerated mortar-bar method test method for aggregates (2016) [9]

- AAR-3.1 Detection of potential alkali-reactivity$38{ }^{\circ} \mathrm{C}$ test method for aggregate combinations using concrete prisms \& AAR-3.2 Method for determining the critical alkali threshold for an aggregate combination (2016) [9]

- AAR-4.1 Detection of potential alkali-reactivity$60{ }^{\circ} \mathrm{C}$ test method for aggregate combinations using concrete prisms (2016) [9]

- AAR-5 Detection of potential alkali-reactivityRapid preliminary screening test for carbonate aggregates (2016) [9]

- AAR-8 Determination of alkalis releasable by aggregates in concrete (2021) [8]

- AAR-10.1 \& 10.2 Determination of binder combinations for non-reactive mix design using concrete prisms - $38{ }^{\circ} \mathrm{C}$ test method (2021) [10]

- AAR-11.1, 11.2 \& 11.3 Determination of binder combinations for non-reactive mix design or the resistance to alkali silica reaction of concrete mixes using concrete prisms $-60{ }^{\circ} \mathrm{C}$ test method (2021) [1]

- AAR-12.1, 12.2 \& 12.3 Determination of binder combinations for non-reactive mix design or the resistance to alkali silica reaction of concrete mixes using concrete prisms $-60{ }^{\circ} \mathrm{C}$ test method with alkali supply (2021) [2]

- AAR-13 Application of alkali-wrapping for concrete prism testing assessing the expansion potential by alkali-silica reaction (2021) [13]
The guidance includes preliminary advice on the interpretation of the findings. The principles are illustrated by the flow charts given in Fig. 1a, b. Guidance on the specialised assessment of carbonate rock aggregates for alkali-reactivity potential is given in "Appendix A". AAR-1 to AAR-5 and AAR-8 include assessment procedures for aggregates, while AAR-10 to AAR-13 include assessment procedures for combinations of aggregates and binders, i.e. performance testing that may be applied to assess mix design requirements when using reactive or potentially reactive aggregates. Information on selection of reference materials and testing accessories is given in "Appendix B", and a list of definitions used in this document may be found in "Appendix C".

In simple terms Alkali-Aggregate Reaction (AAR) is a variety of chemical reactions which develop within the concrete. Reactive constituents within certain types of aggregates are susceptible to attack by $\mathrm{OH}^{-}$ions present in the alkali pore solution in the concrete. Water in the concrete acts both as a solvent and a carrier for the hydroxyl and alkali ions, and is also required to enable the reaction products to expand. There are two main types of AAR; AlkaliSilica Reaction (ASR) and Alkali-Carbonate Reaction (ACR):

- $A S R$ is a reaction in concrete between the alkali hydroxide and certain types of concrete aggregates, containing reactive silica constituents, such as opaline silica, chert, microcrystalline or deformed quartz and some volcanic glass. The reaction produces gel causing deleterious expansion and cracking of the concrete.

- $A C R$ is a reaction in concrete between the alkali hydroxide and certain argillaceous dolomitic limestone aggregates accompanying dedolomitization. Under certain conditions, deleterious expansion of the concrete may occur. Some examples of AAR involving carbonate aggregates are now recognised as a particular variety of ASR, rather than ACR. It is thought possible that cases of AAR involving carbonate rocks can include either or both ACR and the variety of ASR arising from cryptocrystalline silica disseminated within the carbonate rock.

The scope of the present document is to explain how the above methods may be used as single tests or in combinations to assess properties of aggregates and 
concrete related to ASR. Review of the use of AAR 6.1 (Guide to diagnosis and appraisal of AAR damage to concrete in structures-Part 1 Diagnosis) [4] \& AAR6.2 (Maintenance and repair, draft not yet published) and AAR-7 (International specification to minimize damage from alkali reactions in concrete) [9] falls outside the scope of the present document.

Guidelines for the avoidance of deleterious ASR may comprise the assessment of single concrete constituents-including the manufacturer's declaration of relevant properties - or the assessment of the combination of such constituents ("performance assessment"), depending on exposure conditions and/or the properties of the constituents.

Below, in connection with the introduction of the individual testing methods, ranges of limit values for expansion of cast specimens (mortar or concrete) are discussed, but adoption of such limit values should follow from practical experience with locally applied materials and environmental conditions. One reason for local definition of limit values is the fact that selection of reference materials may strongly influence the outcome of some of these tests. This includes the range of properties of locally available test cement, even for CEM I (EN 197-1) (Ordinary Portland Cement-OPC). Replacing CEM I with a composite cement as test cement for aggregate, due to lack of availability of the former, may completely change the bias for limit values definition. Valuable information for limit value consideration, e.g. on climatic conditions, will be provided by research initiated during the same RILEM technical committee but is yet to be completed and published.

\subsection{Aggregate assessment}

The AAR related properties of an aggregate depend on the actual conditions for its intended use and should be considered within the context of concrete mix design requirements, exposure conditions, safety level and service life. Aggregates from both new and existing sources frequently require to be assessed for their suitability for use in concrete. The investigation of AAR potential is one essential part of the assessment, but it should be recognised that, in many cases, other properties will have important potential influence on the performance of aggregates. Therefore, the evaluation of AAR potential should not be carried out in isolation, but rather as a specialised extension to the routine assessment of the suitability of an aggregate.

It should be acknowledged that the AAR related properties of an aggregate cannot always be made according to a straight-forward assessment. Some minerals require assessment according to one specific methodology, while others require different ones. Sometimes a step-wise approach and the combination of more than one testing method must be applied. Even then it will often be difficult to make quantitative statements with respect to degree of reactivity. A prerequisite for the selection of an adequate assessment methodology is first-hand experience of the correlation between the aggregate's field performance and its behaviour in any test to which it is subjected.

Consideration of ASR potential is complicated by the so-called 'pessimum' behaviour of some aggregates, whereby expansion of concrete is maximised at a certain level of reactive constituent in the aggregate and progressively reduced for both greater and lesser levels. It is consequently important for AAR assessment to consider the total combination of coarse and fine aggregates, rather than only the individual materials.

Any expansion exceeding the criteria given for the tests used in the assessment of AAR potential are taken possibly to be caused by ASR and/or by reactions involving carbonates (ACR). However, it is recommended that, in the case of assessing aggregates without previously verified properties post-test petrographic examination of specimens should be carried out to confirm that any expansion was caused by a form of AAR.

In addition to inherent reactivity, some aggregates, irrespective of whether they are themselves reactive or non-reactive, can influence the reactivity potential of a concrete mix by releasing alkalis that are additional to those derived primarily from the cement. Certain exposure conditions may also contribute to increased concrete alkali content. The AAR-8 procedure [8] for determining any content of releasable alkalis in aggregates has been developed for assessing such properties, but should be used with care and as part of an overall assessment, since results are indicative only of potential alkali release, irrespective of grading and actual exposure conditions. The verification of actual release under field conditions is still subject to research. 


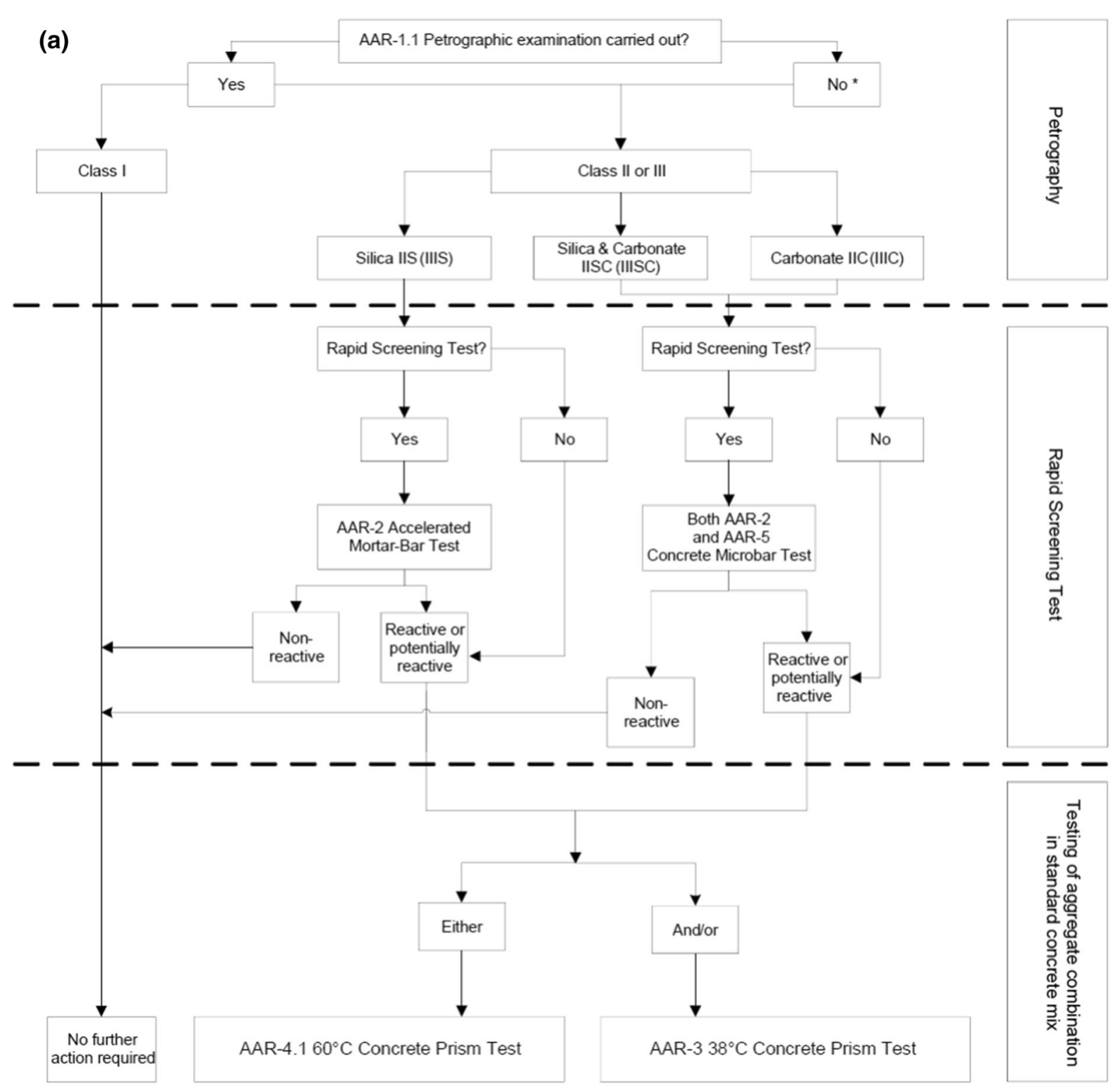

* If no petrographic examination has been carried out, assume Class II (or III)

Fig. 1 a Integrated Aggregate Assessment Scheme (AAR-1 to AAR-5). b Performance assessment scheme for combinations of aggregates and binder

\subsection{Principle of aggregate assessment}

Any assessment of an aggregate combination for AAR potential should ideally commence with petrographic examinations of the component aggregates, which establishes their individual and combined compositions and identifies the types and concentrations of any potentially reactive constituents. This usually allows an aggregate combination to be assigned to one of three categories, as follows:

- Class I-very unlikely to be alkali-reactive

- Class II-potentially alkali-reactive or alkalireactivity uncertain

- Class III-very likely to be alkali-reactive 


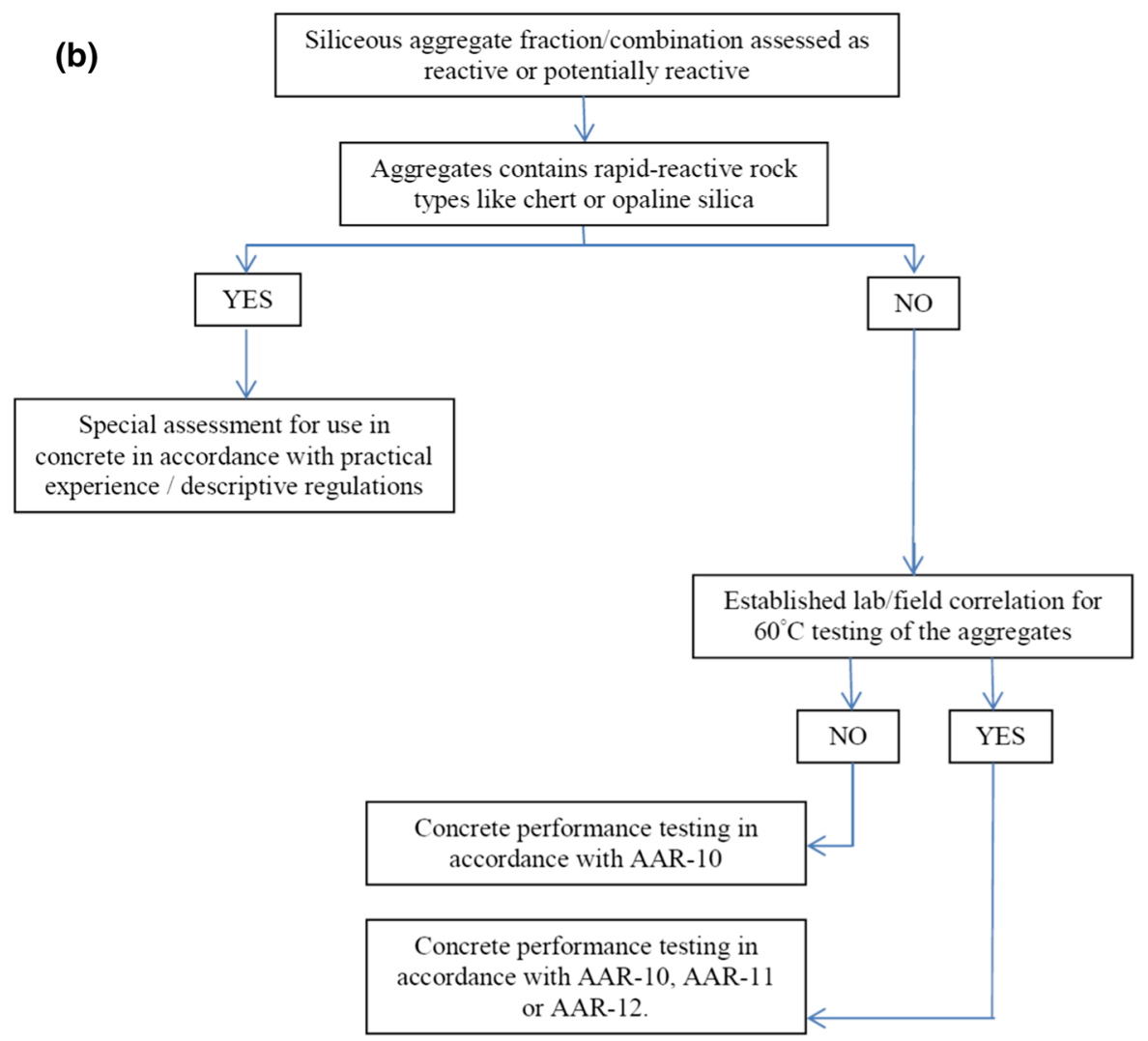

AAR-13 may be used in combination with AAR-10 and/or AAR-11

Fig. 1 continued

The petrographic examination may also be used to select further assessment procedures for which the type of material has been qualified:

In the case of new aggregate sources, Class II is common and further testing will be required. For existing aggregate sources, when experience of use can be taken into account for local applications, Classes I or III are more often possibilities.

When petrography indicates Class II (or Class III), it becomes necessary to decide on the most appropriate further tests. Aggregates which are either mainly siliceous, or carbonates with a potentially reactive silica content, are designated Class II-S or III-S and may be subjected to the RILEM aggregate expansion tests (see Fig. 1a).

Porous aggregates or aggregates containing chert or opaline silica may not exhibit similar expansion behaviour as other aggregates in expansion tests and may better be assessed by alternative methods (see below).
Aggregates which are either mainly carbonate, or mixtures including potentially reactive types of carbonate, are designated Class II-C or III-C and may be subjected to the specialised procedures for aggregates comprising or containing carbonate materials, especially if the carbonate includes the mineral dolomite (calcium-magnesium carbonate). Some aggregates of mixed composition might be designated Class II-SC or III-SC and should thus be subjected to the procedures described for carbonate aggregates (AAR-2 and AAR5 in combination (see Fig. 1a), but also see the guidance provided in "Appendix A").

Separate forms of silica will exhibit different degrees of reactivity, i.e. leading to various rates of reaction. The proportion of silica that can lead to the most damaging reaction will depend on the reactivity of the silica. For some forms of silica (e.g. chert and opaline silica), only a small amount could lead to the "pessimum" behaviour of aggregates. For slower 
reactive forms of silica, it is more common that increased amounts of silica lead to greater reaction.

Because of this, it is important that the whole aggregate combination is assessed, as amounts of reactive silica that are innocuous in either the fine or coarse aggregate alone may be damaging in the combined aggregate. Conversely, apparently reactive fine or coarse aggregates may sometimes be safe when used in combination.

In the case of the RILEM expansion tests for assessing combinations of aggregates, AAR-3 is regarded as the reference test, on the basis of accumulated experience of its use in various forms. AAR-3 requires a lengthy period, up to 12 months or more, for reliable results to be obtained and even AAR-4.1 (accelerated by a higher storage temperature) requires up to 5 months. Alternatively, AAR-10 [10] or AAR-11 [1] may be used with CEM I only (this is particularly useful for input to performance testing, see below). Still, good correlation between the relatively short-term results of test methods and long-term field performance has not been demonstrated for all aggregates, so that guidance on the use of test methods in practice must consider aggregate properties as well as exposure conditions. The selection of either AAR-3 or AAR-4.1 should recognise that the degree of aggregate reaction in the laboratory test may differ from field behaviour, depending on mineralogy: Some aggregates being triggered to react at $60{ }^{\circ} \mathrm{C}$ may not react at $38{ }^{\circ} \mathrm{C}$ (i.e. neither in $38{ }^{\circ} \mathrm{C}$ testing methods, nor in the field). Also, the applicability of quantitative criteria (lab/field correlation) of the concrete prism tests for assessing aggregates containing chert has not been demonstrated to the same extent as for other aggregates.

Due to the lengthy procedures of AAR-3 and AAR4.1, the AAR-2 and AAR-5 tests have been developed as screening tests, i.e. for the optional provision of an earlier indication of the possible outcome.

At present, following petrographic assessment, it is considered unwise to rely solely on the results of the accelerated screening tests and the preliminary indications from those methods should always be confirmed by one of the concrete prism tests. Also, practical experience has suggested that the accelerated mortar-bar test (AAR-2) might be unreliable for certain aggregates, including Class II-S aggregates containing porous flint (a type of chert) as a potentially reactive constituent. Greater experience with the accelerated mortar-bar test may, in due course, enable this advice to be modified. Various tests exist in different countries (Denmark, France, Germany, Poland, UK) [11] for the detection of various types of chert/flint/opaline silica, one of which is TI-B 51 [12].

All sources of natural aggregates exhibit both systematic and random variations in composition and properties. Suitability assessments have therefore to be repeated periodically and this is particularly the case with evaluation of AAR potential. After a first classification of an aggregate, however, screening tests may be used for on-going assessment, providing there is no evidence of geological change in the source.

\subsection{Concrete mix design assessment/ASR performance testing}

ASR performance testing provides an opportunity for assessing the properties of a particular concrete composition, i.e. the combination(s) of aggregates and binders. For example, the application of performance testing acknowledges the potentially ASRmitigating properties of composite cements or additions (SCMs) and may be used to develop non-ASRsusceptible concrete mix designs for reactive or potentially reactive aggregates. It may also be used indirectly to assess aggregate properties for a range of mix designs where the classification of the aggregate itself is difficult. However, establishing performance testing requires definition of acceptance criteria, based on review of adequate field conditions and establishing a correlation between such field conditions and laboratory test results. Currently, assessing the concrete composition by performance testing must be done, applying a specified range of w/b-ratios in order to prevent artefacts, e.g. internal drying of the test samples (shrinkage) or excessive leaching of alkalis during testing, from causing misleading results.

AAR-10 [10], AAR-11 [1], AAR-12 [2] and AAR13 [13] may be used for performance assessment (see Table 1). AAR-10 is a $38{ }^{\circ} \mathrm{C}$ test, suitable for combinations of binders and aggregates, where the aggregates are adequately assessed at this temperature (see section 1.2). AAR-11 offers the same concept, but testing at $60{ }^{\circ} \mathrm{C}$ and may be applied to mix design incorporating aggregates that may be adequately assessed at this temperature level. AAR-12 is also a $60{ }^{\circ} \mathrm{C}$ test, but offers a procedure taking into account 
Table 1 Key features of AAR-10 [10], AAR-11 [1], AAR-12 [2] and AAR-13 [13]

\begin{tabular}{|c|c|c|c|c|}
\hline Feature & AAR-10 & AAR-11 & AAR-12 & AAR $-13^{a}$ \\
\hline $\begin{array}{l}\text { Temperature/ } \\
\text { aggregates } \\
\text { with proven } \\
\text { lab/field at; }\end{array}$ & $38^{\circ} \mathrm{C}$ & $60^{\circ} \mathrm{C}$ & $60^{\circ} \mathrm{C}$ & $38 / 60^{\circ} \mathrm{C}$ \\
\hline $\begin{array}{l}\text { Minimum test } \\
\text { duration }\end{array}$ & 1 year & 20 weeks & 20 weeks & - \\
\hline $\begin{array}{l}\text { Nominal } \\
\text { specimen } \\
\text { size }(\mathrm{mm})\end{array}$ & $400 \times 100 \times 100$ & $250 \times 75 \times 75$ & $250 \times 75 \times 75$ & - \\
\hline$w / b$-ratio & 0.48 & 0.48 & 0.48 & - \\
\hline Wrapping & None & None & None & $\begin{array}{l}\text { Wrapping with defined } \\
\text { alkali solution content }\end{array}$ \\
\hline $\begin{array}{l}\text { Length } \\
\text { comparator }\end{array}$ & Vertical/horizontal & Vertical/horizontal & Vertical/horizontal & - \\
\hline $\begin{array}{l}\text { Storage } \\
\text { containers }\end{array}$ & $\begin{array}{l}\text { Containers with airtight } \\
\text { lids that hold three } \\
\text { specimens and are } \\
\text { stored in a room or } \\
\text { cabinet maintained at } \\
38^{\circ} \mathrm{C}\end{array}$ & $\begin{array}{l}\text { Rectangular sealable } \\
\text { stainless steel containers } \\
\text { stored within a reactor that } \\
\text { maintains conditions of } \\
60{ }^{\circ} \mathrm{C} \text { and approx. } 100 \% \\
\text { RH. Containers may hold } \\
\text { three or six specimens }\end{array}$ & $\begin{array}{l}\text { Rectangular sealable } \\
\text { stainless steel containers } \\
\text { stored within a reactor that } \\
\text { maintains conditions of } \\
60{ }^{\circ} \mathrm{C} \text { and approx. } 100 \% \\
\text { RH. Containers may hold } \\
\text { three or six specimens }\end{array}$ & $\begin{array}{l}\text { Containers that hold } \\
\text { three specimens and } \\
\text { are stored in a room or } \\
\text { cabinet, allowing } \\
\text { application of the } \\
\text { wrapping }\end{array}$ \\
\hline $\begin{array}{l}\text { External } \\
\text { alkalis }\end{array}$ & None & None & $\begin{array}{l}\text { Storage in } \mathrm{NaCl} \text { solution (in } \\
\text { addition to cyclic drying } \\
\text { and storage over water) }\end{array}$ & $\begin{array}{l}\text { Only as included in } \\
\text { wrapping }\end{array}$ \\
\hline $\begin{array}{l}\text { Alkali } \\
\text { leaching } \\
\text { assessment }\end{array}$ & Optional & Optional & n.a & n.a \\
\hline $\begin{array}{l}\text { Targeting all } \\
\text { binder types }\end{array}$ & Yes & Yes & Yes & Yes \\
\hline $\begin{array}{l}\text { Procedure } \\
\text { included for } \\
\text { porous flint/ } \\
\text { chert or } \\
\text { pessimum } \\
\text { aggregates }\end{array}$ & No & No & No & No \\
\hline $\begin{array}{l}\text { Explanatory } \\
\text { annexes } \\
\text { included }\end{array}$ & $\begin{array}{l}\text { Extensive explanatory } \\
\text { notes and references }\end{array}$ & $\begin{array}{l}\text { Extensive explanatory notes } \\
\text { and references }\end{array}$ & $\begin{array}{l}\text { Extensive explanatory notes } \\
\text { and references }\end{array}$ & $\begin{array}{l}\text { Calculation of alkali } \\
\text { concentration to } \\
\text { include in wrapping }\end{array}$ \\
\hline
\end{tabular}

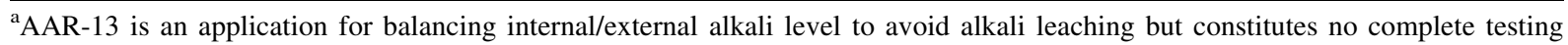
procedure and, hence, must be combined with one of the concrete prism tests to provide a complete testing concept

external alkali supply/exposure in a direct way. If the in-field review for establishing limit values (lab/field relation) includes a sufficient number of structures exposed, for example, to de-icing salts (or other saline conditions), the application of performance tests may provide a generic, regulatory solution. In such cases, AAR-10 and AAR-11, together with their applied acceptance limits, may be considered implicitly to take external exposure to alkalis into account (for the relevant concrete quality range).

AAR-13 is basically founded on the same principles as AAR-10 \& AAR-11 (including the needs for lab/field correlation), but in addition offers a procedure whereby external wrapping of the test specimens contains an alkali concentration, aiming to compensate for alkali leaching during testing. It assumes that 
the internal alkali concentration can be estimated, or the alkali concentration of the wrapping maintained at a conservative level, in order to establish the right balance between the interior and the exterior of the test specimens. The relevance of AAR-13 includes the critical issue of avoiding the alkali content dropping below any threshold level for the aggregate during the test.

It is essential, in all of these performance tests, that the total alkali content in the mix does not drop below the threshold level of the incorporated aggregates(s) during the test, as a result of alkali leaching. The level of alkali leaching may be determined during or after the test for control. In practice, one may expect that the use of SCMs will exhibit less alkali leaching, compared with that of a basic CEM I mix design. Prolonged testing or reduced specimen size beyond those of the test specifications will inevitably increase alkali leaching.

Performance testing may, for example, be used for: Assessing minimum amounts of SCMs required for the use of a specific aggregate source or fraction at a given (maximum) alkali level;

- Assessing alkali threshold with CEM I of a specific aggregate (combination) (AAR-10);

- Assessing/developing specific mix designs, i.e. job mixes intended for a specific project but with limitations with respect to w/b-ratio; or

- Assessing general mitigation-effective cement composition design — or a minimum amount of SCM - for a given maximum alkali level and a group of, or regionally worst-case scenario, aggregate combinations.

Especially the last option allows the possible development of more generally applicable procedures, saving time and reducing assessment efforts during routine operations. Within a region or country, sets of pre-qualified solutions may be developed and integrated into more general specification-based regulations.

\subsection{Principles of ASR performance testing}

Concrete test prisms are prepared with the selected aggregate and binder combination(s). Sodium hydroxide is often added to the mix, when deemed necessary to enhance the alkali level (alkali "boosting") in order to investigate the effect of later increases in total alkali level in concrete production during project operation. Such alkali level increase may arise from quality variations especially of the cement, or from a later deliberate increase in cement content. Alkali boosting may also be used to compensate for expected alkali leaching during testing, to ensure that the total alkali level remains above that of the alkali threshold level of the aggregate.

The prisms are stored under conditions expected to promote and accelerate ASR reaction. Reaction is detected by longitudinal expansion of the concrete specimens.

In AAR-10.1 \& AAR-11.1, a selected aggregate fraction or combination is tested together with a binder candidate, to establish safe use of that aggregate. Testing is performed from a "conservative view" only within the target range of use of the aggregate (its range of expected variations). The alkali level for which the aggregate is tested is the sum of the alkalis from the cement clinker contribution and that from any chemical admixtures and other alkali-releasable sources. If needed for the testing objectives, additional levels of SCM content are added to the investigation. Hence, the main variables may be the level of alkali or the level of such SCM in the range of mix designs. The test output will be a maximum alkali level or a minimum SCM content, separately or in combination, to use with this aggregate combination.

In AAR-10.2 \& AAR-11.2, a selected cement or binder composition is tested together with a reference or worst-case scenario aggregate combination and grading, to establish a generic cement/binder solution in the area of interest. The binder combination reflects a selected level/ratio of cement clinker and the intended minimum level/ratio, type and source of $\operatorname{SCM}(\mathrm{s})$. The alkali level for which the aggregate is tested is the sum of the alkalis from the cement clinker contribution and that from any chemical admixtures and other alkali-releasable sources. Several alkali boosting levels may be tested to investigate the effect of later modification of the concrete composition or changes in the alkali contribution from its constituents. The test output will be a maximum level of alkali content for which the binder composition is validated for use in combination with aggregates that are available (or intended for use) in the area.

Restrictions for validation apply to the properties of the $\operatorname{SCM}(\mathrm{s})$ (type/source); the output from the 
investigation is valid for $\mathrm{SCM}(\mathrm{s})$ of the same type and source as investigated.

AAR-12 is essentially the same concept as AAR11 , but the storage conditions have been modified to evaluate directly the impact of de-icing salts (3-\% or $10 \% \mathrm{NaCl}$ solution) and agents. The method is based on a procedure applied by the federal German road authorities to test aggregates and concrete compositions for concrete road pavements to avoid ASR damage. During the testing period, the test specimens are exposed to cyclic immersed and air storage conditions.

AAR-13 introduces the concept of wrapping to concrete performance testing, to be applied together with concrete prism tests. The concept is suitable for different temperatures (both $38^{\circ} \mathrm{C}$ and $60{ }^{\circ} \mathrm{C}$ ) and different specimen sizes. The concrete specimens are wrapped with a paper containing a water-based alkali solution, mimicking the alkali concentration of the pore solution of the concrete. By using this procedure, the exchange (leaching) of alkalis between the concrete and the surroundings is minimized. In addition, the wrapping contributes to maintaining a certain moisture level in the prisms.

AAR-13 may be regarded as an "app" to combine with compatible concrete prism tests. The AAR-13 test description contains only the procedures for wrapping and the calculations for alkalinity of the solution. The alkali concentration in the wrapping is determined at a conservative level in the sense that the total alkali content of the SCM is included in the alkali solution applied for the wrapping.

\subsection{Aggregate samples}

Laboratory investigations are only reliable if the samples are representative. It is therefore important to ensure that the sample used for AAR assessment is properly representative of its source. In the case of an operating existing quarry, it is usually appropriate to take suitably representative samples from the current stockpiles of processed aggregates, following the sampling procedures given in national and international standards for aggregate testing.

In the case of a new or prospective quarry, it might be more appropriate for an experienced geologist to take rock lump samples directly from natural outcrops and/or to drill cores from rock bodies to be extracted as quarrying for aggregates proceeds. Different rock types would be tested separately or in controlled combinations at the discretion of the field geologist: the test samples should endeavour to represent the aggregates which will be produced for actual use.

Guidance on the taking of representative samples is included in AAR-1 [9] (petrographic examination).

It is envisaged that suitable reference materials, including high-alkali cement (CEM I, if possible) and both reactive and non-reactive aggregates, are made available on a national/regional basis (relevance), to facilitate assessment under long-term stable conditions (series of aggregate sampling and assessment over time) with AAR-2, AAR-3, AAR-4.1 and AAR-5.

\subsection{Cement and SCM samples}

Whenever adequate for assessing aggregates in mortar or concrete tests (AAR-2, AAR-3 etc.), a reference cement may be defined and applied (for a region or country). This will minimize uncertainties due to changes in chemical or physical properties influencing the availability of free alkalis or changes in pore structure and shrinkage potential, even if these parameters may have secondary effects only.

Cement samples intended for use in performance testing should be selected in accordance with expected quality level during use, referring to source and key properties such as composition, alkali level, fineness and strength level. Expected future increases in alkali level may be compensated for in the test by alkali boosting. For composite cements, it is required that the cement sample used for testing is in the lower intended range for its content of any SCM (conservative approach).

When using SCM for performance testing, the assessment should be considered source specific, at least for fly ash and slag. Alkali boosting to compensate for future alkali increase of siliceous fly ash and slag is considered to be even more conservative than the above similar boosting for cement alkalis.

\section{Part two: introduction to testing methods: features, application and acceptance limits}

\subsection{Petrographic examination: AAR-1.1 \& 1.2}

A procedure is given in AAR-1 [9], and its petrographic atlas companion AAR-1.2 [19], for the 
petrographic examination and classification of aggregate samples for AAR potential. This procedure enables any potentially alkali-reactive constituents to be identified and, if necessary, quantified. The identification is based primarily upon basic petrography or mineralogical type(s), supported, whenever possible and appropriate, by local experience.

As explained earlier, petrographic examination will lead to one of three Classes: I, II or III. In the case of Class II (or Class III), it will also be necessary for the petrographic examination to determine whether the aggregate is wholly or partly siliceous (Class II-S or III-S), or wholly or partly carbonate (Class II-C or IIIC), or possibly a combination containing significant proportions of both siliceous and carbonate materials (Class II-SC or III-SC). If petrography is not available or was inconclusive, the material being evaluated should be regarded as being Class II.

The procedure described in AAR-1.1 \& 1.2 results in a petrographic analysis for the sample under investigation, whereby each particulate constituent has been petrologically (or mineralogically) identified, its relative proportion determined and its alkalireactivity status (judged innocuous or potentially reactive) established. This information is then used to classify the aggregate sample, for the purposes of the AAR assessment, into one of the three categories I, II or III, suffixed -S, -C or -SC as appropriate.

Acceptance and experience with reactive constituents differ between countries, and thus, final assessment and classification should follow any national or regional experiences, recommendations and specifications. Therefore, it is recommended that, whenever possible, petrographers should apply local guidance and/or local experience to assist with this classification.

In the case of Class II and III aggregate samples, the material is additionally sub-classified according to the siliceous and/or carbonate nature of the potentially reactive constituents, using the following definitions:

- Classes II-S \& III-S aggregate samples contain particulate constituents judged to be potentially alkali-silica reactive (ASR).

- Classes II-C \& III-C aggregate samples contain particulate carbonate constituents judged to be potentially reactive.

- Classes II-SC \& III-SC aggregate samples contain both particulate constituents judged to be potentially alkali-silica reactive (ASR) and particulate carbonate constituents judged to be potentially reactive.

In the case of Class II-S or III-S materials, it is then appropriate to carry out the RILEM test methods for alkali-silica reactivity (ASR): AAR-2 for short-term screening purposes and AAR-3 for any long-term confirmation. The $60{ }^{\circ} \mathrm{C}$ AAR-4.1 test may be considered as an alternative to AAR-3.

In the case of Class II-C, II-SC, III-C or III-SC materials, it is instead appropriate to carry out the AAR-5 short-term screening test procedures for aggregates comprising or containing carbonate aggregates. Again, any long-term confirmatory testing will involve either or both of the AAR-4.1 and AAR-3 methods. Additional information on the assessment of carbonate rock aggregates is given in "Appendix A".

Practical experience has indicated, however, that the applicability of AAR-2 for correct assessment of Class II-S or III-S aggregates containing more than $2 \%$ by mass of porous flint (chert) as a potentially reactive constituent is questionable. Such aggregates are widely encountered, for example, in several northern European countries/regions, including Belgium, Denmark, Sweden (in Scania), Baltic, the Netherlands and the United Kingdom. Some porous flint (chert) aggregate combinations that have been established as being expansively reactive in actual structures were not detected as being expansive in the accelerated mortar-bar test. Class II-S or III-S aggregates found by petrography to contain more than $2 \%$ porous flint (chert), therefore, should be assessed by special methods developed particularly for these types of aggregates. Various test methods have been developed, see Sect. 1.3, but fall outside the scope of the present document. The applicability of such aggregates using the AAR-3 or AAR-4.1 tests has not yet been sufficiently demonstrated. Alternatively, without field experience such aggregates should be accepted as being potentially alkali-reactive and precautions taken to minimise the risk of ASR damage to any concrete in which the material is used.

\subsection{Accelerated mortar-bar testing of aggregates: AAR-2}

An accelerated screening test for ASR, using mortarbar specimens, is given in AAR-2 [9]. The use of the 
method is questionable for porous flint (chert) aggregates (see above).

Experience has shown that the test procedure is able to detect pessimum behaviour and it is therefore recommended that a series of tests is carried out, in which the test aggregate is mixed with a non-reactive material in a range of proportions. Guidance on this procedure is given in the annex to AAR-2. However, it is not certain that the pessimum proportion indicated by the test corresponds with that exhibited by a comparable concrete. Hence, care must be taken when interpreting the results-as well as for providing recommendations.

Criteria for the interpretation of the results of AAR2 have not yet been finally agreed. However, on the basis of trials carried out by RILEM on aggregates of known field performance from various parts of the world, it seems that results in the test (after the standard 16-days, using 'long thin' $25 \mathrm{~mm} \times 25$ $\mathrm{mm} \times 250-300 \mathrm{~mm}$ specimens) of less than $0.10 \%$ are likely to indicate non-expansive materials, whilst results exceeding $0.20 \%$ are likely to indicate expansive materials. It is not currently possible to provide definitive interpretative guidance for results in the intermediate range $0.10-0.20 \%$ and, for all practical purposes in the absence of additional local experience, aggregates yielding AAR-2 results in this range will need to be regarded as being potentially alkalireactive.

These tentative criteria refer to the 'long thin' specimen size presently given in AAR-2, although it is possible that the 'short fat' (or 'short thick') specimen size $(40 \mathrm{~mm} \times 40 \mathrm{~mm} \times 160 \mathrm{~mm})$ will become preferred in due course, and this is the recommended specimen size in AAR-5. At present, optional versions of AAR-2 are available for both the long thin (AAR2.1) and short fat (AAR-2.2) specimens. Based on the findings of the EU 'PARTNER' research programme [7], on average short fat specimens produce lower values than long thin specimens over the same time period; the mean ratio of expansion of short fat to long thin specimens is in the region of $0.75-0.80$. However, this ratio may vary considerably; thus, for many aggregates it would give a misleading result if a fixed ratio is used to extrapolate from one type of specimen to the other. It should be considered that the mechanisms involved during testing are not linear and thus, correlations between test results with different specimen dimensions will also differ over time.
It follows that, in the case of aggregate combinations producing AAR-2 results (after the standard 16-day test) of $0.10 \%$ or higher for long thin specimens (AAR-2.1) or $0.08 \%$ or higher for short fat specimens (AAR-2.2), precautions will probably need to be taken to minimise the risk of ASR damage to any concrete in which the material is used unless concrete prism testing or field performance indicates otherwise.

There is evidence from several countries that some slow reactive aggregates are not detected using the above criteria. There have been examples reported of granitic aggregates which exhibit low expansion, in spite of having caused damage in the field. By contrast, it is experienced that some basaltic aggregates, containing volcanic glass, exhibit greater expansion in the test, compared with field behaviour.

It has been suggested that assessment of the rate of expansion might be an alternative method for interpreting the AAR-2 test, especially in the case of uncertain results, and tentative recommendations for this approach are given in the annex to the AAR-2 method (also see [17], for possible criteria).

The most important lesson from such studies, however, is that criteria (dimensions of specimens, test duration, expansion limits) must be based on knowledge from field behaviour for relevant groups of aggregates. It should also be noted that some reactive aggregates are not adequately detected in AAR-2, while some react in AAR-2 even if not reacting in the field (see the background references [15], [20], [22], [23] and [25]). In the latter case, final evaluation should be carried out by applying AAR-3 or AAR-4.1.

\section{$2.338^{\circ} \mathrm{C}$ Concrete prism testing of aggregates: AAR-3}

A $38{ }^{\circ} \mathrm{C}$ concrete prism test method for ASR and ACR is given in AAR-3 [9]. This test can be used in two ways: as a standard test for evaluating the alkalireactivity of an aggregate combination (AAR-3.1) at a fixed alkali level (with CEM I) or as a test for ranking, based on 'alkali threshold' of a particular aggregate combination (AAR-3.2). There is, however, evidence that leaching of alkalis from the relatively small concrete specimens used in these tests can result in an overestimation of alkali threshold value, compared with that found in field concretes. Due to the relatively higher alkali leaching from the smaller AAR-3 prisms, compared with the larger AAR-10 prisms, direct alkali 
threshold in performance testing context may preferably be assessed by AAR-10 (see later). For absolute threshold value determination even with AAR-10, actual leaching may have to be controlled/measured (Chapter 12-Annex F of AAR-10).

In AAR-3.1, coarse and fine test aggregates are tested together in a standard mix combination and, where pessimum behaviour is suspected (or where it is unknown whether pessimum behaviour might be expected), repeat tests can be carried out in which the coarse and fine fractions are variously replaced by a non-reactive material. In some cases, it might be considered more desirable to conduct the tests using the actual aggregate combination planned for a particular project, although, in such cases, the usual interpretation criteria could be less applicable.

The test should always be carried out using the cement and alkali contents stipulated in AAR-3.1, including the higher cement content permitted for certain types of aggregate combinations. The interpretation criteria suggested below for AAR-3 however, would not be in any way applicable to concrete mixes with lower cement and/or alkali contents. For the assessment of actual aggregate and cement (binder) combinations, refer to AAR-10 -13.

In AAR-3.2, the test is used as a means of establishing the alkali threshold ranking/classes (not absolute level) at which a particular aggregate combination begins to exhibit a deleterious expansion. In this test, at least three concrete mixes with alkali levels in increments normally between, for example, 2 and $5 \mathrm{~kg} / \mathrm{m}^{3} \mathrm{Na}_{2} \mathrm{Oeq}$. are tested. The alkali threshold is the alkali level at which there is a deleterious expansion (according to the criteria discussed below). This threshold may be used to designate the aggregate reactivity class of the combination according to AAR7.1 (the international specification for minimising the risk on ASR) [9].

In case of using AAR-3.2 for direct threshold level determination, it is strongly recommended that adequate safety margins are applied, based on local experience. Chapter 11, Annex E of AAR-10 outlines potential sources of errors particularly relevant to ASR expansion tests that should be considered for setting safety margins.

Criteria for the interpretation of the results of AAR3 necessarily cannot be agreed across all aggregate types and exposure or climate conditions. However, on the basis of trials carried out by RILEM on aggregate combinations of known field performance from various parts of the world, it has been found that the expansion limits used in the test vary based on local experience (actual aggregate types and climate conditions), but generally range between 0.03 and $0.05 \%$ for non-reactive aggregates (usually after 12 months). Results exceeding $0.10 \%$ indicate expansive materials. It is not currently possible to provide definitive interpretative guidance for results in the intermediate range. For all practical purposes in the absence of additional local experience, aggregates yielding AAR3 results in this range will need to be regarded as being potentially alkali-reactive.

In many cases, expansion will have ended or the rate of expansion becomes greatly reduced by the end of the standard 12-month test period. This may be due to lack of additional reactive constituents in the aggregate or to alkali leaching; it is known that alkalis will gradually escape from the test specimens, reducing the rate of reaction. The total alkali content may drop below the aggregate's threshold level value, demonstrating again the need to control or assess the degree of leaching, see AAR-10 for reference. However, in some cases, expansion might still be occurring at 12 months, suggesting that the above criteria possibly could be exceeded during an extended period of testing. It is not possible to provide general, definitive guidance on the interpretation to be placed on such behaviour in the test. Again, criteria must be set, acknowledging practical experience with the aggregate type from the field.

\section{$2.460{ }^{\circ} \mathrm{C}$ Concrete prism testing of aggregates:} AAR- 4.1

A $60{ }^{\circ} \mathrm{C}$ concrete prism test method for assessing ASR- and ACR-properties of aggregates has been developed, as an accelerated version of the AAR-3 test, for evaluating the reactivity of an aggregate combination-AAR-4.1 [9]. Note that testing at $60{ }^{\circ} \mathrm{C}$ may in some cases initiate reaction of aggregates that would not occur at $38{ }^{\circ} \mathrm{C}$ or in the field, as well as overestimating the reaction rate or level, compared with those observed in the field. Again, alkali threshold in a performance testing context may preferably be assessed by AAR-10 (see later).

Criteria for the interpretation of the results of AAR4.1 should involve the same concerns as above. However, on the basis of an initial assessment of the 
AAR-4.1 trials carried out by TC 191-ARP on aggregate combinations of known field performance from various parts of the world, it seems that a maximum expansion in the test of $0.03 \%$ at 15 weeks, alternatively 20 weeks for moderately reactive aggregates (see "Appendix C" for definition), indicates a non-reactive aggregate combination. It follows that, in the case of aggregate combinations producing AAR4.1 results greater than $0.03 \%$ at 15 (20) weeks, in the absence of local experience to the contrary, precautions should be taken to minimise the risk of ASR damage to any concrete in which the material is used.

\subsection{Carbonate aggregate testing: AAR-5}

An accelerated screening test procedure for aggregates comprising or containing carbonate material has been developed as AAR-5 [9] and has been assessed by an international trial. In this procedure, the aggregate material is subjected to testing using both the AAR-2 mortar-bar test and a new derivative test using 'concrete-bar' specimens, in which a $4 / 8 \mathrm{~mm}$ aggregate grading is used instead of the $0 / 4 \mathrm{~mm}$ grading used in AAR-2. In this application, both the AAR-2 and AAR-5 procedures employ 'short fat' specimens (NB: the term 'concrete-bar' should not be confused with 'concrete prism').

Interpretation of the AAR-5 findings is based upon comparing the results of the two test methods. In typical ASR, the mortar-bar (AAR-2) method may be expected to produce greater expansion than the 'concrete-bar' (4/8 mm aggregate) method. However, investigations and trials have shown that expansion is greater in the 'concrete-bar' (4/8 mm aggregate) test in the case of reactive carbonate aggregates (i.e. aggregates comprising crushed carbonate rock or natural aggregates containing a substantial proportion of carbonate rocks and minerals) that have been associated with carbonate-related expansion in concrete structures. Additionally, it has been found that these materials are not necessarily identified using the AAR-2 method alone. Therefore, in the AAR-5 procedure, if the 'concrete-bars' (4/8 $\mathrm{mm}$ aggregate) expand more than the conventional AAR-2 mortarbars (0/4 $\mathrm{mm}$ aggregate), the reactivity of the aggregate is probably not of the normal ASR type and further investigation using the longer-term AAR-4.1 or AAR-3 concrete prism tests will be required.
Interpretation of the comparison between the AAR2 and AAR-5 results may be summarised as follows (in all cases referring to the 'short-fat' specimen option):

AAR-2 $>0.08 \%$

- $\mathrm{AAR}-5<\mathrm{AAR}-2=$ potential ASR

- $\mathrm{AAR}-5 \geq \mathrm{AAR}-2$ = possible combination of ASR \& carbonate reaction

AAR- $2<0.08 \%$

- $\mathrm{AAR}-5 \geq \mathrm{AAR}-2=$ possible carbonate reaction

- $\mathrm{AAR}-5<\mathrm{AAR}-2$ = no further testing

Further guidance on the specialized assessment of carbonate rocks and aggregates for reactivity potential is given in "Appendix $\mathrm{A}$ " (see also the background references [14], [18], [21], [24] and [26]).

2.6 Potential release of alkalis from aggregates: AAR-8

AAR-8 [8] has been developed and refined for assessing the releasable alkali content from aggregates. Various methods have been suggested and used previously, mostly based upon extraction by a calcium hydroxide solution, but none of these have been considered adequately to replicate the possible release of alkalis from the aggregates within concrete. AAR-8 is based upon extraction using an alkali solution (sodium hydroxide for extracting potassium and potassium hydroxide for extracting sodium), in each case saturated with calcium hydroxide. It is, however, still considered pre-mature to provide guidance on the interpretation and application of AAR- 8 findings. The main reason for this is lack of validation of how the outcome of the test may be applied to predict alkali release from the aggregates under field conditions. AAR-8 may be used to assess relative alkali release potential, but cannot at the current stage be used in a context e.g. of limiting total alkali content levels in concrete. Work on verification of releasable alkali content under field conditions is in progress.

\section{$2.738{ }^{\circ} \mathrm{C}$ Performance test: AAR-10}

The basic test principles in AAR-10 [10] have been widely applied on concrete mix designs containing CEM I (OPC) and additions like fly ash, slag and silica 
fume, or composite cement with the same constituents, combined with aggregates that may be applied to AAR-3 (see above discussion on AAR-3 for limitations). This test is considered particularly suitable when no unambiguous lab/field relation for the particular aggregate candidate has been established for $60{ }^{\circ} \mathrm{C}$ testing. The test document includes advice on how to deal with alkali leaching during testing as well as other potential sources of errors.

Concrete test prisms are prepared with the selected aggregate and binder combination(s). Sodium hydroxide is added to the mix when necessary to enhance the alkali level (alkali boosting). The prisms are then stored for 12 or 24 months to promote ASR. Establishing the alkali threshold value of the aggregate candidate or "family" with AAR-10 using CEM I (OPC) will often be valuable as a starting point for drafting the test programme.

In AAR-10.1, a selected aggregate fraction or combination (Application 1/Chapter 5.1.3) is tested together with a binder candidate, to establish safe use of that aggregate. The test output will be a maximum alkali level or a minimum SCM content, separately or in combination, to use with this aggregate combination. Testing is performed from a "conservative view" within the target range of use of the aggregate (its range of expected variations): The applicability of the test results is limited to the maximum content of the aggregate fraction/combination assumed to be most susceptible in the test (NB: Consider the discussion on pessimum ratios included above under AAR-3).

The alkali level for which the aggregate is tested is the sum of the alkalis from the cement clinker contribution and that from any chemical admixtures and other alkali-releasable sources. Several alkali boosting levels may be tested to investigate the effect of later modification of the concrete composition or changes in the alkali contribution from its constituents. If needed for the testing objectives, additional levels of $\mathrm{SCM}(\mathrm{s})$ content are added to the investigation. Hence, the main variable (scope of testing) may be the level of alkali or the level of such SCM in the planned range of mix designs. For the selected aggregate combination, the investigation will typically include three to five levels of SCM or alkali content (or more if both parameters are combined).

In AAR-10.2, a selected cement or binder composition is tested together with a reference or worst-case scenario aggregate combination and grading, to establish a generic cement/binder solution in the area of interest. The test output will be a maximum level of alkali content for which the binder composition is validated for use in combination with aggregates that are available (or intended for use) in the area. The binder combination reflects a selected level/ratio of cement clinker and the intended minimum level/ratio, type and source of $\mathrm{SCM}(\mathrm{s})$.

The alkali level for which the aggregate is tested is the sum of the alkalis from the cement clinker contribution and that from any chemical admixtures and other alkali-releasable sources. Several alkali boosting levels may be tested to investigate the effect of later modification of the concrete composition or changes in the alkali contribution from its constituents. For the selected binder combination(s), the investigation will typically include three to five levels of alkali content.

In both AAR-10.1 and AAR-10.2, a standard waterto-binder ratio $(\mathrm{w} / \mathrm{b})$ of 0.48 is specified that is intended to maximize the concrete prism expansion during the test, irrespective of the w/b used in the field. This is done in order to avoid artefacts like shrinkage due to internal drying in the test specimens.

In AAR-10.1, expansion test results are plotted against the content level of the SCM, if adequate one chart per alkali level, in order to determine the minimum SCM content for the target alkali level. In AAR-10.2, expansion test results are plotted against the alkali content level. In both cases, the linear intersection with a pre-determined expansion limit value (test criterion) determines the minimum SCM content or maximum alkali content level, respectively, of the cement/binder and aggregate combination.

Again, acceptance criteria must be based on relevant field conditions. Special concern in this case is the need to differentiate, if possible, test duration and/or limit values on the types of binder. In some cases, it is adequate to combine an early, conservative limit option with that of a prolonged testing period and less conservative limit. Chapter 11, Annex E of AAR10 outlines potential sources of errors particularly relevant to ASR expansion tests that should be considered for setting safety margins.

\section{$2.860{ }^{\circ} \mathrm{C}$ Performance test: AAR-11}

Regarding features and applicability, AAR-11 [1] is a direct parallel to AAR-10 but is considered 
particularly suitable when an unambiguous lab/field relation for the particular aggregate candidate has been established for $60{ }^{\circ} \mathrm{C}$ testing.

AAR-11.3 provides a special version whereby a specific "job mix" concrete mix design (including fixed aggregate grading) is submitted for testing. For job mixtures with water-to-binder ratio $(\mathrm{w} / \mathrm{b})$ below 0.40 , interpretation of data from AAR-11.3 is complicated, due to issues with self-desiccation and reduced moisture transport, for example.

The consideration regarding limit values of AAR10 apply here as well, but the actual expansion values (if both test procedures are allowed for the same aggregate or concrete composition) will often be higher with AAR-11. This should be reflected in limit values, but is not always applied in national regulations. Again, alkali threshold in a performance testing context may preferably be assessed by AAR-10.

\section{$2.960{ }^{\circ} \mathrm{C}$ Performance test with external alkali supply: AAR-12}

In AAR-12 [2], AAR-11 is modified in such a way that it includes ten cycles of drying, immersion in an alkali containing test solution and sealed reactor storage. The test was primarily introduced for the assessment of concrete road and airfield pavements with extensive seasonal application of de-icing agent. The same three applications as for AAR-11 are covered.

\section{$2.1038^{\circ} / 60{ }^{\circ} \mathrm{C}$ Performance test with alkaline wrapping: AAR-13}

AAR-13 [13] specifies a wrapping procedure to be used in conjunction with concrete prism tests (CPT). This approach is proposed to prevent alkali leaching from the test specimens during the exposure period in the testing cabinet/reactor. The concept was originally developed for application on a Japanese CPT test [6], investigating job mix concrete containing pessimum aggregates. Using this approach, limit values will probably need to be reconsidered.

Various effects in addition to the concrete mix design may influence leaching behaviour, e.g. temperature changes. The objective of applying the alkalicontaining wrapping is to maintain the alkali content as constant as possible. Basically, it is possible to apply alkali wrapping for many concrete prism tests (CPTs), and AAR-13 may be regarded as an optional application to compatible CPTs. The alkali solution to be applied for the wrapping is calculated and to some extent conservative, especially when the concrete mix design includes SCM; the total alkali content of the SCM is included in the alkali solution applied for the wrapping.

\subsection{Precision of the RILEM methods}

The overall precision of the RILEM methods AAR-2 (see below), AAR-3 and AAR-4.1 were assessed in an inter-laboratory trial as part of the PARTNER Programme [7] following the procedure set out in ISO 5725-94 [5]. However, the evaluation of the precision of AAR-3 and AAR-4.1 was conducted on a wrapped prisms version only and not relevant for the current procedures. The precision data for RILEM AAR-8 was assessed as part of the work in RILEM TC 258-AAA (2014-2019).

\section{AAR-2}

Eight laboratories took part in the AAR-2 assessment using three aggregates chosen to give a low, medium and high value. The results of the trial are summarized in Table 2.

\section{AAR-8}

4 laboratories took part in the round robin testing (RRT) with RILEM AAR-8 using five aggregates with relatively low alkali release potentials. Results from the RRT (not published yet) are given in Table 3 .

\section{Part three: conclusions and conceptual framework}

\subsection{Conclusions and input for regulatory framework}

Petrographic examination (AAR-1.1 \& 1.2) should be carried out in connection with all initial assessments. On some occasions this will lead directly to definitive outcomes, either Class I 'unlikely to be alkalireactive', or Class III 'very likely to be alkalireactive'. In many cases, however, petrographic examination will lead to an indefinite outcome, Class II 'potentially alkali-reactive', and further testing will be required. 
Table 2 Results from the inter-laboratory trial with AAR-2 in the PARTNER programme [7]

\begin{tabular}{lccc}
\hline Expected reactivity for aggregate in inter-laboratory trial & $\begin{array}{l}\text { Low/medium } \\
\text { Aggregate 1 }\end{array}$ & $\begin{array}{l}\text { Medium } \\
\text { Aggregate 2 }\end{array}$ & $\begin{array}{l}\text { High } \\
\text { Aggregate 3 }\end{array}$ \\
\hline AAR-2 (short fat prisms, 28 days)* & & & 0.467 \\
General mean expansion $m(\%)$ & 0.271 & $2.3 \%$ & 0.592 \\
Repeatability $\operatorname{COV}\left(\mathrm{s}_{\mathrm{r}}\right)$ & $3.4 \%$ & $24.3 \%$ & $16.5 \%$ \\
Reproducibility $\operatorname{COV}\left(\mathrm{s}_{\mathrm{R}}\right)$ & $22.4 \%$ & & \\
\hline
\end{tabular}

*General definitions

$r=$ repeatability. This is a measure to determine the spread in results obtained between the individual prisms, tested at the same laboratory, same aggregate combination and same concrete

$\mathrm{R}=$ Reproducibility. This is a measure to compare the difference in the mean value obtained between the different laboratories

$\operatorname{COV}(\mathrm{sR})=$ Coefficient of variation for Reproducibility. By using the coefficient of variation (COV) one relates the spread to the actual expansion. The COV is the standard deviation divided by the mean value. The COV $(\mathrm{sR})$ is thus used to compare the difference in the spread between the participating laboratories. Similarly, the COV(sr) is used to compare the spread within one single test carried out at one laboratory. In this case, the spread between the three prisms or bars will determine whether it is correct to average their results or if the test has to be remade or only two of the single results should be averaged; all depending on the instructions in the test method

Siliceous aggregates (and carbonate aggregates with siliceous content) may be further assessed for ASR, usually using first the short-term screening test (AAR-2), then the $60{ }^{\circ} \mathrm{C}$ accelerated concrete prism test (AAR-4.1), which can be interpreted after 15 (20) weeks. If required, the longer-term (12-24 months) $38{ }^{\circ} \mathrm{C}$ concrete prism test (AAR-3) may be carried out and is sometimes considered to be ultimately more reliable, being less accelerated by comparison with most actual exposure conditions. The findings of the concrete prism tests should always take precedence. The findings of the $38{ }^{\circ} \mathrm{C}$ tests should take precedence if this is in accordance with findings of field history or from lab/field studies. The application of the AAR-2 test alone for the assessment of Class II aggregates containing porous flint (chert) as a potentially reactive constituent is questionable. The criteria for some moderately reactive aggregate types may also need to be modified.

Carbonate aggregates (and siliceous aggregates with a significant carbonate content) may be further assessed using the AAR-5 short-term ( 2 or 3 weeks) screening procedure, which will identify any aggregate reactivity that is probably not of the normal ASR type and indicate when further investigation using the longer-term AAR-4. 1 or AAR-3 concrete prism tests will be required. Specific guidance on assessing carbonates is given in "Appendix A".

In addition to assessment of an aggregate combination for reactivity potential, the aggregates may be tested for releasable alkali content using the AAR- 8 method, the significance and usefulness of which are still subject to verification.

A flow chart for aggregate assessment incorporating the above testing methods is provided in Fig. 1a. This could be used for designing local framework specifications, considering products available in the market.

Reactive or potentially reactive siliceous aggregates may in many cases still be used if the concrete mix design is assessed safe by performance testing. Figure $1 \mathrm{~b}$ provides an overview on how performance testing methods may be applied within the regulatory framework.

Table 3 Results from the inter-laboratory trial with AAR-8 in RILEM TC 258-AAA (not published yet)

\begin{tabular}{|c|c|c|c|c|c|}
\hline Type of aggregate & $\begin{array}{l}\text { Aggr.1 } \\
\text { Mylonite }\end{array}$ & $\begin{array}{l}\text { Aggr. } 2 \\
\text { Granite }\end{array}$ & $\begin{array}{l}\text { Aggr. } 3 \\
\text { Altered granite }\end{array}$ & $\begin{array}{l}\text { Aggr. } 4 \\
\text { Gneiss }\end{array}$ & $\begin{array}{l}\text { Aggr. } 5 \\
\text { Cataclasite }\end{array}$ \\
\hline \multicolumn{6}{|l|}{ AAR-8 (26 weeks) } \\
\hline General mean alkali release $\left(\% \mathrm{Na}_{2} \mathrm{O}_{\mathrm{eq}}\right)$ & 0.064 & 0.035 & 0.037 & 0.035 & 0.065 \\
\hline Standard deviation $S D\left(\% \mathrm{Na}_{2} \mathrm{O}_{\mathrm{eq}}\right)$ & 0.007 & 0.002 & 0.004 & 0.006 & 0.006 \\
\hline Reproducibility $\operatorname{COV}\left(s_{R}\right)$ & $11 \%$ & $6 \%$ & $11 \%$ & $17 \%$ & $9 \%$ \\
\hline
\end{tabular}


Since real performance of a given material combination in the field is both exposure class and climate dependent, and because acceleration by temperature in the laboratory to a varying extent may represent (or exaggerate) eventual behaviour under field conditions, the selection of test procedure and testing acceptance criteria must be based on correlation between laboratory testing (careful selection of methods) and field conditions. The testing acceptance criteria (such as expansion limits) must also be based on correlation between laboratory testing and field conditions.

Altogether, the drafted framework, together with adequate field surveys and external exposure sites in different climatic regions [3], will provide a good tool for assessing aggregates, aggregate combinations or concrete mix design for classifying the categories of:

- Acceptable for general or application specific use

- Acceptable for use proving minimum requirements are met

- Not safe to use

\subsection{Limitations-disclaimer}

This recommendation has been prepared by professionals, ensuring that the content is in accordance with state-of-the-art when the work was completed. The publication has been subject to a formal RILEM TC internal inquiry. Errors or omissions may however still occur.

The recommendation is valid under the assumption that the publication is used by persons with the necessary professional competence, and with the understanding of the constraints and assumptions that have been taken into account.

RILEM or the TC is not responsible for incorrect interpretation and use of the content of the publication, nor for direct or indirect consequences of any errors or omissions in the publication, or the use of the content of the publication.

\section{Compliance with ethical standards}

Conflict of interest The authors declare that they have no conflict of interest.

\section{Appendix A - Assessment of carbonate rock aggregates for reactivity potential}

\section{Scope}

This Appendix describes procedures for the assessment of potentially reactive carbonate rocks in concrete. The procedures include those in AAR-1.1 \& 1.2, which does not include specific guidance on the assessment of carbonate rocks for reactivity in concrete. As a result of undergoing the procedures described in this Appendix, carbonate rocks should be classified according to one of the following classes:

- Very unlikely to be alkali-reactive-Class I

- Alkali-reactivity uncertain-Class II

- Very likely to be alkali-reactive-Class III

It is very important that the petrographic analysis is carried out by a qualified geologist with experience of materials used for concrete and good local knowledge of alkali-reactive aggregates, minerals and in this case especially carbonate rocks.

\section{Definitions}

Alkali carbonate reaction (ACR)

Chemical-physical expansive reaction in concrete between certain impure coarse grain-sized dolomitic carbonate rocks and the cement paste. The reaction appears to be associated with dedolomitization and an associated swelling reaction, but is not yet fully understood and documented.

Note A1: The reaction might occur concurrently with Alkali-Silica Reaction (ASR) caused by the same or different particles in an aggregate. Some researchers suggest that ASR is the only expansive reaction in reacted carbonate aggregates.

Carbonate rock

A rock composed of more than $50 \%$ by mass of carbonate minerals such as calcite or dolomite. They are sedimentary or metamorphic, and very rarely igneous (carbonatites) in origin. 
Carbonate sedimentary rocks

Calcareous rock is a rock containing an appreciable amount of calcium carbonate. It can be sedimentary limestone (e.g. chalk, tufa or calcarenite). Dolomitic limestone contains 10-50\% dolomite and 50-90\% calcite. Dolomite rock (dolomite) contains more than $50 \%$ of the mineral dolomite. Dolomite occurs in crystalline and microcrystalline forms. The term "dolostone" is synonymous with dolomite rock, but has not gained universal acceptance.

Carbonate rock deposits can often contain intermixed layers of clay, shale, sandstone or siltstone. Silicification of carbonate rock deposits with dispersed crypto- and micro-crystalline quartz or opal is not uncommon.

Metamorphic carbonate rocks

Metamorphic carbonate rock is termed marble. Dolomitic marble is composed mostly of the mineral dolomite

\section{Dedolomitization}

A process resulting from chemical weathering, diagenesis, metamorphism or hydrothermal alteration, wherein part or all of the magnesium component in a dolomite or dolomitic limestone is consumed in the formation of magnesium hydroxides and silicates (e.g. brucite, forsterite), resulting in an enrichment in the calcite content.

Chemical reaction of dolomite in concrete

Dolomite can be unstable in concrete under certain conditions. The instability and decomposition of dolomite in concretes produce more stable phases, such as calcite and brucite. It could be the result of the following reaction:

$$
\underset{\text { dolomite }}{\mathrm{CaMg}\left(\mathrm{CO}_{3}\right)_{2}}+2 \mathrm{M}(\mathrm{OH})=\underset{\text { calcite }}{\mathrm{CaCO}_{3}}+\underset{\text { brucite }}{\mathrm{Mg}(\mathrm{OH})_{2}}+\mathrm{M}_{2} \mathrm{CO}_{3}
$$

where $M$ is an alkali metal

It remains uncertain whether or not this dedolomitization process alone can sometimes cause damage to concrete.

\section{Principles}

The AAR-1.1 \& 1.2 petrographic examination method describes the visual recognition and quantification techniques for rocks and mineral constituents of aggregate sources with special emphasis on their potential for alkali-reactivity. This Appendix gives supplementary information and methods for assessing carbonate rocks for potential reactivity in concrete.

Thin-sections (optionally polished thin-sections) stained for carbonate rocks should be prepared and used to determine the types of carbonate rocks. The procedures for carbonate rocks are summarised in Fig. 2. The procedure is generally used for aggregates originating from quarries dominated by carbonate rocks.

Note A2: Crystalline carbonate rock without dolomite and impurities should be assessed unlikely to be reactive and further testing is not necessary. Carbonate aggregates intended to be used only as fines (sand) in concrete are unlikely to exhibit ACR but would still need to be assessed for ASR potential.

The procedure allows for the additional use of 3 optional methods when carbonate rocks have been identified in thin section:

1. X-ray fluorescence analysis (XRF),

2. X-ray diffraction analysis (XRD),

3. Scanning Electron Microscopy (SEM) with Energy Dispersive X-ray analysis (EDX).

Note A3: Detection of dolomite and the potential degree of dedolomitization (and reaction products) can be made using the following techniques:

1. XRD, using an internal standard of very wellknown d-spacing to determine the d-spacing of dolomite.

2. Petrography, using alizarin-red dye, to determine zoning, crystal shape, partial dedolomitization or iron oxides stains as well as EMPA, SEM/EDX.

Rather than proceeding with XRF analysis, XRD analysis and/or SEM/EDX/WDX analysis, this procedure also includes direct application of screening tests according to AAR-5 or even the longer-term AAR-3 or AAR-4.1 concrete expansion tests. 


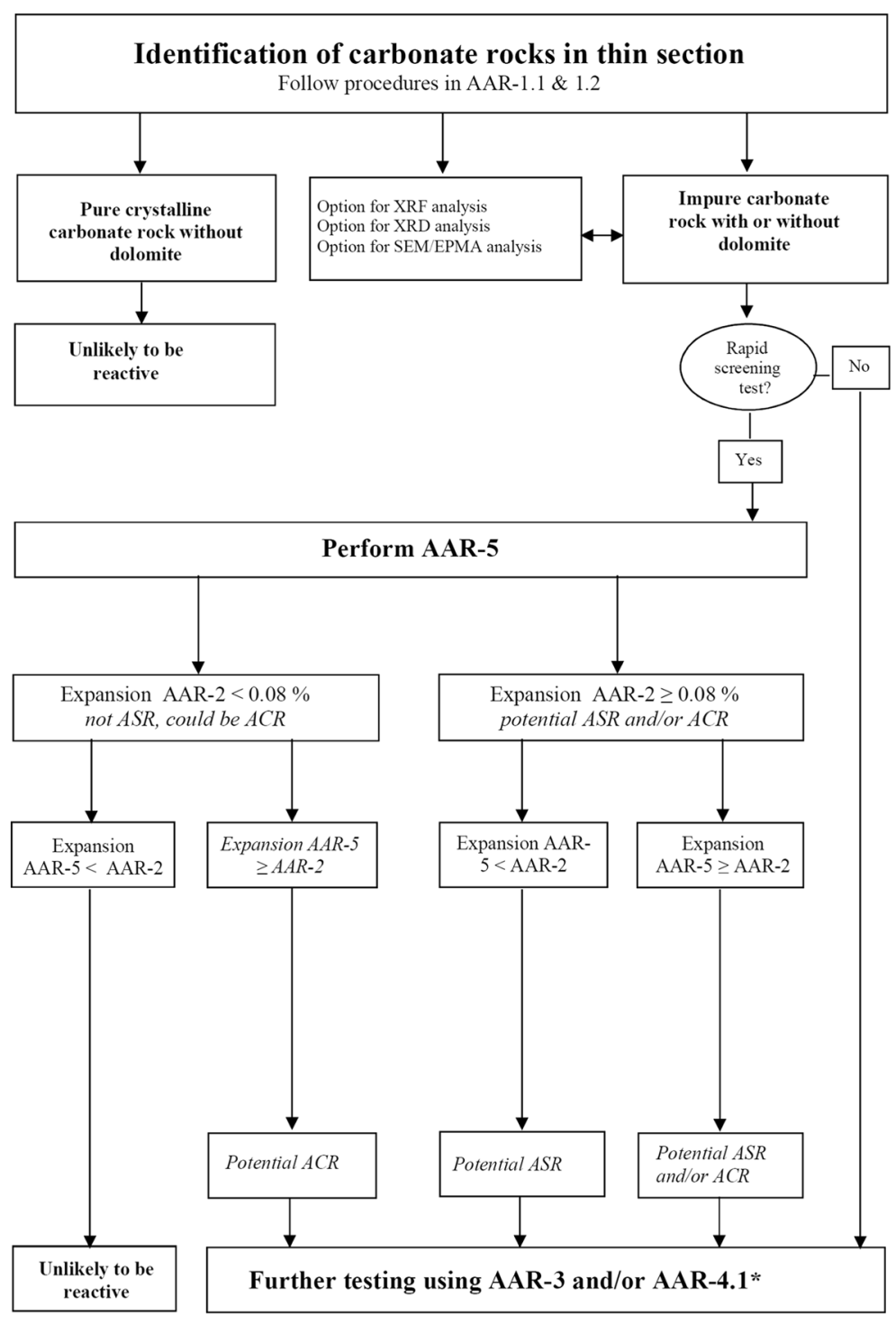

* There is limited experience in using AAR 4.1 for carbonate rocks/aggregates

Fig. 2 Flow chart for AAR assessment of carbonate rocks

\section{Assessment using XRF analysis (optional method)}

When carbonate minerals are identified by thinsection, an X-ray fluorescence (XRF) analysis on the bulk sample might be carried out. Minimum elements to be analysed are calcium and magnesium to indicate the carbonate minerals (calcite and dolomite), and aluminium to indicate the possible presence of clay minerals (see also note A5 below).

For the assessment of reactivity, the calcium/magnesium oxide ratio should be calculated, and the ratio plotted in Fig. 3 against the aluminium oxide content.
Two possibilities will result, based upon empirical observations in Canada, namely to be "considered potentially expansive" or "considered non-expansive". Because of limited experience with the method outside Canada, a further assessment of possible expansion should be carried out according to AAR-5.

\section{Assessment using XRD analysis (optional method)}

When carbonate minerals are identified by thinsection, an X-ray diffraction (XRD) analysis on a 
bulk sample might be carried out (see AAR-1.1 \& 1.2). Generally, the major $(>5 \%)$ and minor minerals $(<5 \%)$ are analysed and reported. Normally XRD analysis is used for qualitative identification of minerals, but can also be used for semi-quantitative measurements.

The carbonate minerals magnesite, dolomite, ferroan dolomite and calcitic dolomite are considered indicative of potentially ACR reactive material. At present, the identification of any detectable quantity of these phases should classify the aggregate sample as "potentially expansive" and further testing according to AAR-5 should then be performed (see Fig. 2).

If ACR indicative minerals have not been identified by the XRD analysis, ACR is unlikely to occur but ASR is still possible. In that case testing according to AAR-2 and/or AAR-3 and/or AAR-4.1 could be performed (see Fig. 2).

Note A4: XRD analysis, which identifies only crystalline materials, will not be able to characterize amorphous constituents (e.g. opal-A, glass, or other non-crystalline constituents).
Note A5: In some carbonate rocks, clay minerals can occur that might also cause problems and non-AAR expansion in concrete. When necessary, clay minerals can be characterised using specialised XRD. In sedimentary carbonate rocks, the total alumina content is also a useful indicator of the amount of clay minerals, since alumina is normally only derived from clay minerals in the absence of feldspars (authigenic or detrital); as a "rule of thumb", clay mineral content is approximately $3 \times$ the content of alumina $\left(\mathrm{Al}_{2} \mathrm{O}_{3}\right)$.

\section{Assessment using SEM/EPMA analysis (optional method)}

When carbonate minerals are identified by thinsection analysis, examination by use of Scanning Electron Microscopy (SEM) and/or Electron Probe Micro Analyser (EPMA) can be carried out (see AAR$1.1 \& 1.2$ ). This examination should be carried out by qualified personnel with knowledge of these techniques. It is recommended to use polished thinsections or polished samples. Elements can be

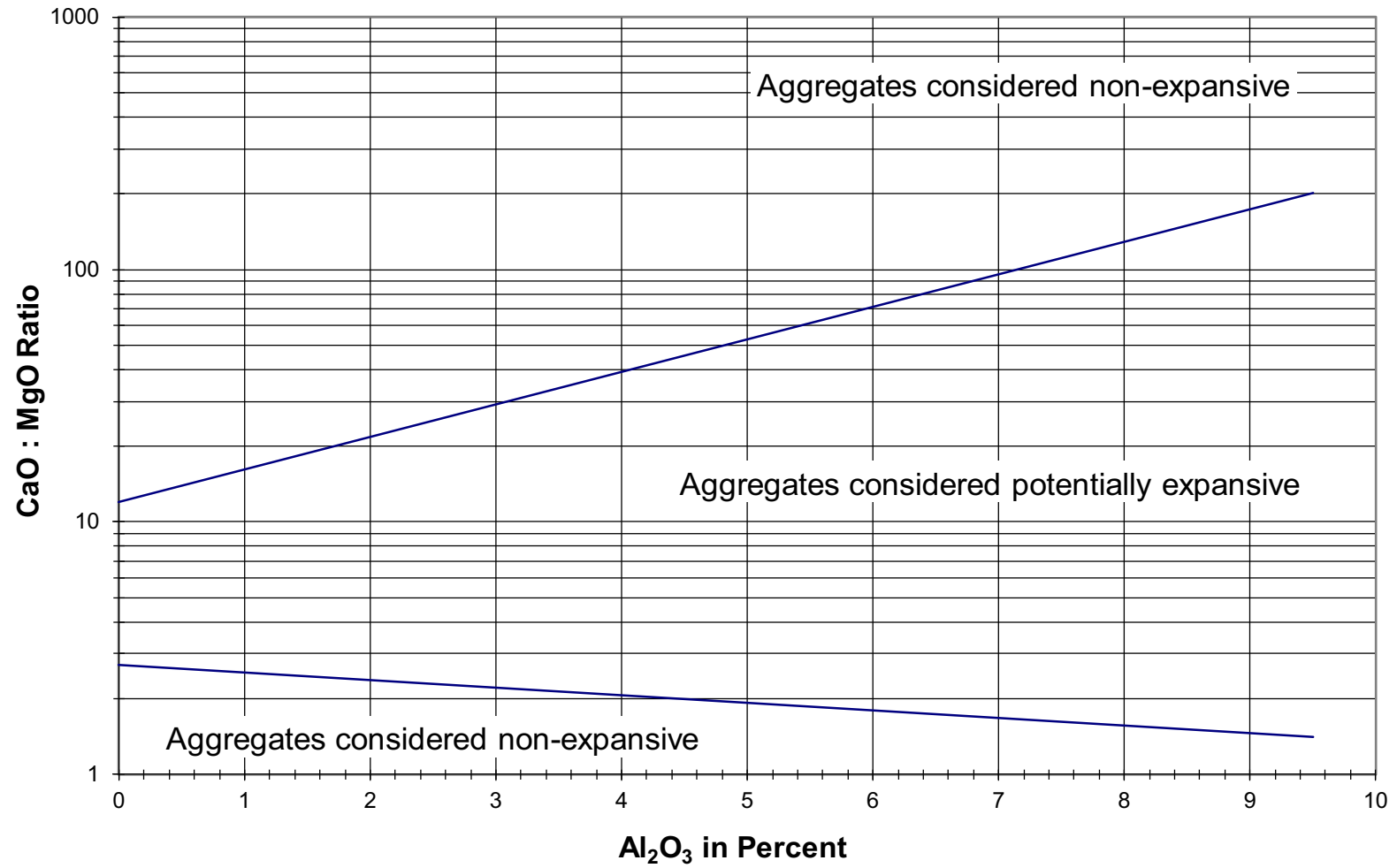

Fig. 3 Suggested interpretation of XRF analysis findings 
detected and quantified by use of Energy Dispersive $\mathrm{X}$-ray (EDX) analyses and minerals by use of Wavelength Diffraction X-ray (WDX) analysis.

Interpretation of results obtained by EDX is the same as given in Fig. 3. Interpretation of results obtained by WDX analysis is the same as given above for XRD.

\section{Assessment of reactivity according to AAR-5}

An accelerated screening test procedure for aggregates comprising or containing carbonate material has been developed as AAR-5 and has been assessed by an international trial.

In this procedure, the aggregate material is subjected to testing using both the RILEM AAR-2 mortar bar test and a new derivative test using 'concrete-bar' specimens, in which a $4 / 8 \mathrm{~mm}$ aggregate grading is used instead of the $0 / 4 \mathrm{~mm}$ grading used in AAR-2. In this application, both the AAR-2 and AAR-5 procedures employ 'short fat' prism specimens $(40 \mathrm{~mm} \times 40 \mathrm{~mm} \times 160 \mathrm{~mm})$.

The interpretation of the AAR-5 findings is based upon comparing the results of these two test methods. In typical ASR, the mortar-bar (AAR-2) method may be expected to produce greater expansion than the 'concrete-bar' method. However, investigations and trials have shown that expansion is greater in the 'concrete-bar' test in the case of carbonate aggregates that have been associated with expansion in concrete structures, and also that these materials are not necessarily identified using the AAR-2 method alone. Therefore, in the AAR-5 procedure, if the 'concretebars' expand more than the mortar-bars, the reactivity of the aggregate is probably not that of the normal ASR type and further investigation using the longerterm AAR-4.1 and/or AAR-3 concrete prism tests will be required.

Interpretation of the comparison between the AAR2 and AAR-5 results (both using the 'short-fat' specimen option) may be summarised as follows (where appropriate, the $0.08 \%$ expansion criterion shown may be replaced by a locally determined value):

RILEM AAR-2 $\geq 0.08 \%$ and:

$$
\text { AAR-5 }<\text { AAR-2 = potential ASR }
$$

AAR-5 $\geq$ AAR $2=$ possible combination of ASR and ACR

RILEM AAR- $2<0.08 \%$ and:

AAR-5 $\geq$ AAR-2 $=$ possible ACR

AAR-5 $<$ AAR-2 = unlikely to be reactive (no further testing necessary)

\section{Assessment of reactivity using AAR-3 and/or AAR- 4.1}

If potential ASR and/or potential ACR are detected, the longer-term (at least 12 months) $38{ }^{\circ} \mathrm{C}$ concrete prism test (AAR-3) may be carried out. Concrete test prisms are prepared from the aggregate combination and are stored in warm, humid conditions for 12 months to promote any alkali-silica reaction or alkali-carbonate reaction. The findings of the concrete prism tests should always take precedence over the results of AAR-2 or AAR-5.

Alternatively, aggregates may be assessed for ASR or ACR using the $60{ }^{\circ} \mathrm{C}$ concrete prism test AAR-4.1, which can be interpreted after 15 weeks. It is envisaged that the AAR-4.1 method might be used as an accelerated version of the AAR-3 test. However, at present there is only limited experience of using the $60{ }^{\circ} \mathrm{C}$ concrete prism method for ACR detection.

\section{Limitations and need for research}

The suggested test procedures are based on the present knowledge of ACR. The optional XRF method (see Fig. 3) is based primarily on Canadian experience and some rarer cases internationally. Therefore, experience and testing of carbonate rocks other than Canadian materials are needed to validate or revise the Canadian procedures and criteria.

The mechanism(s) of ACR is (are) not fully understood and more research is needed on this issue. Carbonate rocks are internationally important and widely used aggregate types for concrete. The guidance given in this Annex will hopefully be a step forward in producing durable concrete with carbonate rocks, but will need to be reviewed periodically and updated as appropriate. 


\section{Annex A References}

\section{Background references}

Antao SM, Mulder WH, Hassan I, Crichton WA, Parise JB, (2004) Cation disorder in dolomite, $\mathrm{CaMg}\left(\mathrm{CO}_{3}\right)_{2}$, and its influence on the aragonite + magnesite $\leftrightarrow$ dolomite reaction boundary. American Mineralogist (89):1142-1147

Dubberke W, Marks VJ, (1987) The relationship of ferroan dolomite aggregate to rapid concrete deterioration, Transportation Research Record No. 1110, Concrete \& Concrete Construction, pp 1-10

García E, Alfonso P, Labrador M, Galí S, (2003) Dedolomitization in different alkaline media: Application to Portland cement paste, Cement \& Concrete Research, 39 (9), 1443-1448.

Galí S, Ayora C, Alfonso P, Tauler E, Labrador M, (2001) Kinetics of dolomite-portlandite reaction: Application to Portland cement concrete, Cement \& Concrete Research, 31:933-939

Gillott JE (1964) Mechanism and kinetic of expansion in the alkali-carbonate rock reaction, Canadian Journal of Earth Science 1:121-145

Grattan-Bellew PE, Mitchell LD, Margeson J, Deng Min, (2010) Is alkali-carbonate reaction just a variant of alkali-silica reaction ACR $=$ ASR?, Cement \& Concrete Research, 40(4):556-562. Special Issue: ICAAR 13, Trondheim, Norway, June 16-20, 2008

Grattan-Bellew PE, Katayama T, (2017) So-called alkalicarbonate reaction (ACR), Chapter 3 in Sims I, Poole AB (editors), Chapter 3, Alkali-Aggregate Reaction in Concrete - a world review, CRC Press (Taylor \& Francis), London: 978-1138-02,756-5 (Hardback), ISBN-1-315-70,895-9 (eBook), pp 63-88

Jensen V, (2009) Alkali carbonate reaction (ACR) and RILEM AAR-0, Annex B: Assessment of potentially reactivity of carbonate rocks, 12th Euroseminar on Microscopy Applied to Building Materials, 15-19 September, Dortmund, Germany

Katayama T (1992) A critical review of carbonate rock reactions - Is their reactivity useful or harmful?, In: Poole, AB (ed), Proceedings of the 9th International Conference on AAR in Concrete, London, UK, pp 508-518

Katayama T (2004) How to identify carbonate rock reaction in concrete, Materials Characterization, 53:85-104

Katayama, T (2010) The so-called alkali-carbonate reaction (ACR)-Its mineralogical and geochemical details, with special reference to ASR, Cement \& Concrete Research, 40(4):643-675. Special Issue: ICAAR 13, Trondheim, Norway, June 16-20, 2008

Lopez-Buendia AM, Climent V, Mar Urquiola M, Bastida J, (2008) Influence of dolomite stability on alkali-carbonate reaction, in: Broekmans, MATM \& Wigum B J (eds), Proceedings of the 13th International Conference on AAR in Concrete (CAAR), Trondheim, Norway, pp 233-242

McCarty DK, Drits VA, Sakharov B, (2006) Relationship between composition and lattice parameters of some sedimentary dolomite varieties, European Journal of Mineralogy (18):611-627
Radjonjic M, Allen GC, (1999) An AFM/ESEM study of dedolomitisation in the alkali-carbonate reaction (ACR), Proceedings of the 7th Euroseminar on Microscopy Applied to Building Materials, Delft, The Netherlands, pp 547-555

Radjonjic M, Allen G, Ragnarsdottir KV, Livesey P, (2000) Novel techniques in a study of the mechanism of dedolomitisation in alkali-carbonate reaction, in: Bérubé MA, Fournier B \& Durand B, Proceedings of the 11th International Conference on AAR in Concrete (ICAAR), Québec, Canada, pp 99-108

Rogers CA (1986) Evaluation of the potential for expansion and cracking of concrete caused by the alkali-carbonate reaction, Cement, Concrete \& Aggregates, CCAGDP $8(1): 13-23$

Swenson EG (1957) A reactive aggregates undetected by ASTM test, ASTM Bulletin, American Society for Testing and Materials (226):48-51

Tang M, Liu Z, Han SF, (1986) Mechanism of alkalicarbonate reaction, in Grattan-Bellew PE (ed), Proceedings of the 7th International Conference on AAR in Concrete (ICAAR), Ottawa, Canada, pp 275-179

Tang M, Lui Z, Lu JN, Han SF, (1989) Kinetic of alkalicarbonate reaction, in Kawamura M, Nishibayashi S, Okada K (eds), Proceedings of the 8th International Conference on AAR in Concrete (ICAAR), Kyoto, Japan, pp 147-152

Tang M, Deng M, Xu Z, (2000) Comparison between alkalisilica reaction and alkali-carbonate reaction, in: Bérubé MA, Fournier B \& Durand B (eds), Proceedings of the 11th International Conference on AAR in Concrete (ICAAR), Québec, Canada, pp 109-118

Tang M, Deng M, (2008) Progress on the studies of alkalicarbonate reaction, in: Tang M, Deng M (eds), Proceedings of the 12th International Conference on AAR in Concrete (ICAAR), Beijing, China, pp 51-59

TongL (1994), Alkali-carbonate rock reaction, Doctoral Thesis, Nanjing Institute of Chemical Technology, Nanjing, China, $219 \mathrm{pp}$

\section{Appendix B - Guide to reference materials}

\section{Preamble}

This guide is intended to provide assistance to any laboratories undertaking the RILEM expansion tests, using either accelerated mortar-bar or concrete-bar aggregate tests (AAR-2 \& AAR-5), the concrete prism aggregate tests (AAR-3 \& AAR-4.1) or the concrete performance tests (AAR-10, AAR-11, AAR-12 \& AAR-13). It includes information on the use of reference cement or reference aggregate materials and various accessories required for conducting the tests. 


\section{Introduction}

The use of reference cement and aggregate materials is not mandatory in the AAR-2, AAR-3, AAR-4.1 and AAR-5 test methods. However, in any testing, the use of reference materials, with reliably known and constant properties or behaviour, may be useful, or stipulated, in certain circumstances, including the following:

- to establish the reliability and accuracy of a new test procedure,

- to assess the competence of a laboratory or the testing personnel,

- to provide reassurance in the case of tests yielding variable results,

- to provide controls for direct comparison with material under evaluation, including: to provide controls for product approval, auto-control and audit testing

In particular in relation to the expansion tests for alkali-aggregate reaction, reference materials may be specifically used as follows:

- Reference High-Alkali Cement EN 197-1 CEM I (if available), alternatively EN 197-1 CEM II with low clinker replacement level): to minimise any variations arising from using cements of different sources, compositions and properties,

- Reference Reactive Aggregate: to provide reassurance to laboratories undertaking tests for the first time, to enable routine checking of testing facilities or their personnel and for use in inter-laboratory precision experiments,

- Reference Non-Reactive Aggregate: to enable a baseline movement to be established for testing facilities and for use in programmes for identifying any pessimum behaviour.

\section{Qualification of reference materials}

High-alkali cement

A source of suitable high-alkali CEM I (EN 197-1) cement is of great convenience, minimizing the need and variable level of alkali boosting for routine testing. If not available, composite cement with low clinker substitution ratio and preferably low quantities of pozzolanic constituents may be chosen. In any case, a stockpile from one single extraction assumed to last for a substantial period of time should be consideredand packed accordingly.

Stockpile replacements, new cement, or new extraction zones may each justify comparison testing for the assessment and verification of constancy of performance and/or adjustments of expansion testing acceptance criteria. Be aware that not only the alkali content but also other chemical and physical property changes may influence the performance.

If appropriate, contact local actors to enquire about the availability of reference cement for use within the intended market area.

Reactive or non-reactive aggregates

Many 'reactive' aggregates have been used in experimental research into ASR, variously using natural and synthetic materials. RILEM recommends that a natural aggregate should be selected and that the preferred material should have exhibited a uniform behaviour in various test methods over an extended time period. The reference aggregate must exhibit expansion in the test methods used.

For "non-reactive" reference aggregates, it is not sufficient to select a product just passing the requirements. Preferably, an aggregate with low potential alkali-release should be selected, for example a pure limestone.

If appropriate, contact local actors to enquire about the availability of reference aggregates for use within the intended market area.

\section{Appendix C - List of definitions}

$A A R$ : In simple terms Alkali Aggregate Reaction is a variety of chemical reactions which develop within the concrete. Reactive constituents within certain types of aggregates are susceptible to attack by $\mathrm{OH}$ - ions present in the alkali pore solution in the concrete. Water in the concrete acts both as a solvent and a carrier for the hydroxyl and alkali ions, and is also required to enable certain reaction products to expand by imbibing water.

ASR: One of the main types of AAR. ASR is a reaction in concrete between the alkali hydroxide and certain type of concrete aggregates, containing 
reactive silica constituents such as opaline silica, chert, microcrystalline or deformed quartz and some volcanic glass. The reaction produces gel causing deleterious expansion and cracking of the concrete. The previously used Alkali Silicate Reaction is now recognised as a slow/late type of ASR.

$A C R$ : Reaction in concrete between the alkali hydroxide and certain argillaceous dolomitic limestone aggregates accompanying dedolomitization. Under certain conditions, deleterious expansion of the concrete may occur. This should not be confused with ASR associated with finely disseminated silica within a carbonate rock.

Alkali threshold level: The minimum nominal alkali level, determined in a concrete expansion test, at which an ASR susceptible aggregate may start to react.

CEM I/EN197-1: In this document as well as in AAR-10, AAR-11 and AAR-12, the term CEM I is linked to definitions given in EN 197-1. This is comparable to (ordinary) Portland cement (OPC), but OPC is a wider term.

High-alkali cement: A non-harmonized term used to characterize cement with alkali content of $1.0 \%$ or higher, often applied as a criterion in connection with testing of ASR-susceptible aggregates.

Low-alkali cement: A non-harmonized term used in some countries to classify CEM I (EN 197-1) or other cement types, often 0.60 for CEM I but sometimes lower or higher. The term is however used in Germany with different alkali content (limit values) depending on slag content.

Moderately reactive aggregate: In this document, consistent with the definition given in Table 1 of ASTM-C1778 [16], but note that there will be effects of specimen dimensions on the expansion values.

Nominal alkali level: The total alkali content of a concrete mix that may be calculated based on contributions from cement including SCMs, admixtures and other constituents, but normally not including any contribution potentially releasable from aggregates.

Pessimum: The pessimum value is the percentage of concentration of a reactive mineral (or aggregate fraction) in an aggregate combination exhibiting the largest damage (expansion) in concrete. The phenomenon is especially applicable to certain minerals where very low concentrations may produce a large degree of damage, while higher concentrations of the same mineral has no or little detrimental effects. This is particularly of concern when combining such aggregates with less reactive aggregates.

Open Access This article is licensed under a Creative Commons Attribution 4.0 International License, which permits use, sharing, adaptation, distribution and reproduction in any medium or format, as long as you give appropriate credit to the original author(s) and the source, provide a link to the Creative Commons licence, and indicate if changes were made. The images or other third party material in this article are included in the article's Creative Commons licence, unless indicated otherwise in a credit line to the material. If material is not included in the article's Creative Commons licence and your intended use is not permitted by statutory regulation or exceeds the permitted use, you will need to obtain permission directly from the copyright holder. To view a copy of this licence, visit http://creativecommons.org/licenses/by/4.0/.

\section{References}

\section{Main references}

1. Borchers I, Lindgård J, Rønning TF, Wigum BJ (2021) Recommendation of RILEM TC 258-AAA: RILEM AAR11: determination of binder combinations for non-reactive mix design or the resistance to alkali-silica reaction of concrete mixes using concrete prisms $-60{ }^{\circ} \mathrm{C}$ test method. Submitted Mater Struct

2. Borchers I (2021) Recommendation of RILEM TC 258-AAA: RILEM AAR-12: Determination of binder combinations for non-reactive mix design or the resistance to alkali-silica reaction of concrete mixes using concrete prisms $-60^{\circ} \mathrm{C}$ test method with alkali supply. Submitted Mater Struct

3. Fournier B, Lindgård J, Wigum BJ, Borchers I (2018) Outdoor exposure site testing for preventing Alkali-Aggregate Reactivity in concrete-a review. In: ICCRRR 2018, 5th international conference on concrete repair, rehabilitation and retrofitting; 2018-11-19-2018-11-21, Cape Town, South-Africa, MATEC Web of Conferences 2018, Volume 199. https://doi.org/10.1051/matecconf/ 201819903002

4. Godart B, de Rooij MR, Wood JGM (2013) Guide to diagnosis and appraisal of AAR damage to concrete in structures, Part 1 Diagnosis (AAR 6.1), RILEM state-ofthe-Art Reports. Springer 2013. ISSN 2213-204X, ISBN 978-94-007-6566-5. 87 pp

5. ISO 5725-94 Accuracy (trueness and precision) of measurement methods and results; Part 1 (revised 2018): General principles and definitions; Part 2 (revised 2019): basic method for the determination of repeatability and reproducibility of a standard measurement method

6. JCI-S-010-2017 (2017) Method of test for alkali-silica reactivity of concrete (In Japanese, see: Kawabata Y, Yamada K, Sagawa Y, Ogawa S (2018) Alkali-wrapped 
concrete prism test (AW-CPT) - New testing protocol toward a performance test against alkali-silica reaction-. J Adv Concr Tech 16:441-460)

7. Lindgård J, Nixon PJ, Borchers I, Schouenborg B, Wigum BJ, Haugen M, Åkesson U (2010) The EU Partner projectEuropean standard tests to prevent alkali reactions in aggregates. Cem Concr Res 40:611-635

8. Menéndez EM, Santos Silva A, Duchesne J (2021) Recommendation of RILEM TC 258-AAA: RILEM AAR-8: determination of potential releasable alkalis by aggregates in concrete. Submitted Mater Struct

9. Nixon PJ, Sims I (2016) RILEM Recommendations for the prevention of damage by Alkali-Aggregate Reactions in new concrete structures, RILEM state-of-the-Art Reports. Springer 2016, ISSN 2213-204X, ISBN 978-94017-7252-5

10. Rønning TF, Lindgård J, Wigum BJ (2021) Recommendation of RILEM TC 258-AAA: RILEM AAR-10: determination of binder combinations for non-reactive mix design using concrete prisms $-38^{\circ} \mathrm{C}$ test method. Submitted Mater Struct

11. Sims I, Poole A (2017) Alkali-aggregate reaction in concrete: a world review. CRC Press, London. ISBN: 978-1138-02756-5 (Hardback), ISBN-1-315-70895-9 (eBook)

12. TI-B 51 (1985) Prøvningsmetode Sands alkalikiselreaktivitet (Testing method alkali silica reactivity of sand), Teknologisk Institut Byggeri, Copenhagen, Denmark (in Danish). 4 pp

13. Yamada K, Kawabata Y, de Rooij MR, Pedersen BM, Brueckner R, Ideker JH (2021) Recommendation of RILEM TC 258-AAA: RILEM AAR-13: application of alkaliwrapping for concrete prism testing to assess the expansion potential of alkali-silica reaction. Submitted Mater Struct

\section{Background references}

14. ASTM C586-11 (2019) Standard test method for potential alkali reactivity of carbonate rocks as concrete aggregates (Rock Cylinder Method), ASTM International, West Conshohocken, PA, USA. 5 pp

15. ASTM C1260-14 (2014) Standard test method for potential alkali reactivity of aggregates (mortar-bar method), ASTM International, West Conshohocken, PA, USA. 5 pp

16. ASTM C1778-20 (2020) Standard guide for reducing the risk of deleterious alkali-aggregate reaction in concrete. ASTM International, West Conshohocken, PA. https:// www.astm.org
17. Berra M, Mangialardi T, Paolini AE (2005) Alkali-silica reactivity criteria for concrete aggregates. Mater Struct 38(April):373-380

18. CSA A23.2-09 (2009) Test methods and standard practices for concrete. 26A, Determination of potential alkali-carbonate reactivity of quarried carbonate rocks by chemical composition. CSA A23.2-2009-26A. Canadian Standards Association, Mississauga, Ontario, Canada

19. Fernandes I, Anjos Ribeiro M, Broekmans MATM, Sims I (2016) Petrographic atlas: characterisation of aggregates regarding potential reactivity to alkalis. RILEM TC 219-ACS Recommended Guidance AAR-1.2, for use with the RILEM AAR-1.1 Petrographic Examination Method, 1 st ed. Springer. XI, $191 \mathrm{pp}$

20. Nixon PJ, Fournier B (2017) Assessment, testing and specification, Chapter 2 in Sims I and Poole AB (editors), Alkali-Aggregate Reaction in Concrete: a World Review, CRC Press (Taylor \& Francis), London: ISBN: 978-1138-02756-5 (Hardback), ISBN-1-315-70895-9 (eBook)

21. Rogers CA (1986) Evaluation of the potential for expansion and cracking of concrete caused by the alkali-carbonate reaction, Ontario Ministry of Transportation, Report EM$75,42 \mathrm{pp}$

22. Rogers CA (1996) Multi-laboratory study of the accelerated mortar bar test for alkali-silica reaction. In: Shayan A (ed), Proceedings of the 10th international conference on alkaliaggregate reaction in concrete (ICAAR), Melbourne, Australia, pp 362-369

23. Rogers CA (1999) Multi-laboratory study of the accelerated mortar bar test (ASTM C1260) for alkali-silica reaction. Cem Concrete Aggreg 21(2):185-194

24. Shehata et al. (2011) The effects of supplementary cementing materials on expansion of concrete containing carbonate aggregates of marginal alkali reactivity. In: 2 nd international engineering mechanics and materials speciality conference, Ottawa, Ontario

25. Shayan A (2007) Field evidence for inability of ASTM C1260 limits to detect slowly reactive Australian aggregates. Aust J Civ Eng 3(1):13-26

26. Williams DA, Rogers CA, (1991) Field trip guide to alkalicarbonate reactions in Kingston, Ontario, Ontario Ministry of Transportation, MI Report 145, $26 \mathrm{pp}$

Publisher's Note Springer Nature remains neutral with regard to jurisdictional claims in published maps and institutional affiliations. 